\title{
A Study of Entrance Surface Air Kerma for Patients Undergoing Chest and Abdomen from Digital Radiography at Chulabhorn Hospital
}

\author{
Atchara Promduang, M.Sc. ${ }^{1}$, Napapong Pongnapang, Ph.D. ${ }^{2}$, Napat Ritlumlert, M.Sc. , \\ Sutthirak Tangruangkiat, M.Sc. ${ }^{1}$, Monchai Phonlakrai, M.Sc. ${ }^{1}$ \\ ${ }^{1} \mathrm{HRH}$ Princess Chulabhorn College of Medical Science, Chulabhorn Hospital, Lak Si, Bangkok 10210, Thailand. \\ ${ }^{2}$ Department of Radiological Technology, Faculty of Medical Technology, Mahidol University, Bangkok Noi, Bangkok 10700, \\ Thailand. \\ Received 4 September 2018 • Revised 3 December 2018 • Accepted 19 December 2018 • Published online 12 February 2019
}

\section{Abstract:}

Objective: The main purpose of this study was to investigate the typical dose for standard-sized patients in chest (posteroanterior; PA) and abdomen (anteroposterior; AP) digital radiography.

Material and Methods: The air kerma was measured by the ionization chamber (Radical Corporation, model 10X6-6) in X-ray equipment manufactured by General Electric Healthcare Definium 8000 System for different kilovoltage peak ( $k V p$ ) settings in each X-ray examination. The entrance surface air kerma (ESAK) was determined in 422 mediumsized patients in different projections: chest (PA) and abdomen (AP), according to the recommended protocol of the International Atomic Energy Agency Technical Report Series Number 457 (Technical Reports Series No. 457 "Dosimetry in Diagnostic Radiology: An International Code of Practice).

Results: The mean entrance surface air kerma values for chest (PA) radiography in female and male patients were 0.08 milligray (mGy) and 0.09 mGy, respectively and for abdomen (AP) radiography for both genders were $0.98 \mathrm{mGy}$ and 1.06 mGy, respectively.

Conclusion: The mean entrance surface air kerma values of this study were less than the diagnostic reference levels from the IAEA 1996, Korea 2007, United Kingdom 2010 and Japan 2015, in all projections. Patient doses (ESAK) in chest (PA) and abdomen (AP) digital radiography at Chulabhorn Hospital were less than the other guidelines, because of the use of a high $\mathrm{kVp}$ technique for the chest and the automatic exposure control for the abdomen. Furthermore, Thai people are smaller than Westerners. We studied in digital radiography only that literally provides lowest radiation dose compares with screen film and computed radiography.

Keywords: abdomen, chest, digital radiography, entrance surface air kerma

Contact: Atchara Promduang, M.Sc.

HRH Princess Chulabhorn College of Medical Science, Chulabhorn

Hospital, Bangkok 10210, Thailand.

E-mail: atcharapromduang@gmail.com
J Health Sci Med Res 2019;37(1):51-60 doi: 10.31584 /jhsmr.201940 www.jhsmr.org 


\section{Introduction}

Currently, radiographic imaging is widely used in medical practice in order to help in diagnosing disease, planning treatments, and following treatment. However, patient doses must be considered carefully, because radiation can be harmful to the patient's health both physically and genetically. ${ }^{1}$ Therefore, the radiation dose should be minimised while giving the most effective result to limit the patient dose and to reduce the risk associated with radiation exposure. ${ }^{1}$ In radiographic procedures, a radiological technologist will determine the technical parameters, which vary depending on the patient's size and the type of $\mathrm{X}$-ray device used. Currently, a digital radiological technique is used instead of the screen-film technique at the Department of Radiology, Chulabhorn Hospital. The digital radiographic technique offers a higher image quality, and better data management than the screenfilm system. In practice, however, when using digital radiographic techniques higher radiation doses are correspondingly possible, because of a broader dynamic range of digital image receptors. ${ }^{2}$ Even though a high level of radiation is used and the patient becomes over exposed to radiation, the image is unlikely to turn too dark or black. According to radiation protection principles, the radiation dose received by a patient should not exceed diagnostic reference levels. ${ }^{3,4}$

Based on the literature review, there are researchers who estimate the patient doses for chest and abdomen radiographic examinations; for example, research by Kim et $\mathrm{al}^{5}$ studied patient dose measurements in diagnostic radiology procedures in Korea. The research found that the mean and third quartile of the entrance surface doses for chest (posteroanterior; PA) radiography were 0.21 and 0.28 milligray (mGy), respectively, and the mean and third quartile of the entrance surface doses for abdomen (anteroposterior; AP) radiography were 2.33 and 2.87 mGy, respectively.

A research study in Thailand by Buncharat and Hamuttiti $^{6}$ studied patient doses in simple radiographic examinations in Trang, Phatthalung and Satun Provinces, in the transition from $X$-ray film to computed radiography. There were 24 hospitals participating in the study. Of all the 24 general $X$-ray units, 15 were computed radiography, 1 was digital radiography, and 8 were using X-ray film. The research found that the third quartile of the entrance surface doses for chest (PA) digital radiography was 0.19 $m G y$, and the third quartile of the entrance surface doses for abdomen (AP) digital radiography was 1.34 mGy.

Wanai and Kongkaew ${ }^{7}$ studied the entrance surface dose level of common diagnostic X-ray examinations at Songklanagarind Hospital in Thailand. The research found that the mean and third quartile of the entrance surface doses for chest $(\mathrm{PA})$ radiography were 0.29 and $0.36 \mathrm{mGy}$, respectively, whilst the mean and third quartile of the entrance surface doses for abdomen (AP) radiography were 2.86 and $3.68 \mathrm{mGy}$, respectively.

Furthermore, the Japan Network for Research and Information on Medical Exposure (J-RIME) ${ }^{8}$ established the first diagnostic reference levels (DRLs) in Japan. DRLs are based on the latest surveys in Japan. The DRLs for 2015 in general radiography found that the third quartile of entrance surface doses for chest (PA) and abdomen (AP) radiography were 0.3 and $3.0 \mathrm{mGy}$, respectively.

Entrance surface air kerma (ESAK) is recommended by the International Atomic Energy Agency (IAEA) as the most appropriate patient dosimetry quantity in simple radiographic examinations. The main purpose of this study was to investigate the typical dose for standard-sized patients in chest (PA) and abdomen (AP) digital radiography, which are frequent procedures at Chulabhorn Hospital. 


\section{Material and Methods}

This research was a prospective study. The air kerma was measured by ionization chamber (Model 10X6-6; Radcal Corporation, Monrovia, CA) and control unit model Radcal Accu-Pro 9096 in X-ray equipment manufactured by General Electric Healthcare Definium 8000 digital radiographic system (GE healthcare, Milwaukee, $\mathrm{WI})$. The measurements of the ESAK were made in 422 patients from October 2017 to May 2018. A total of 422 male and female patients were recruited for this study and divided into 2 groups according to radiographic examination, gender, and weight as shown in Table 1.
The study of these patients was approved by the Human Research Ethics Committee, Chulabhorn Research Institute. Written informed consent was obtained from each patient before measuring patient thickness for radiographic examination.

Patient data collection consisted of general information, including patient weight, patient thickness $\left(t_{p}\right)$ as measured at the center of the $\mathrm{X}$-ray beam, technique parameters used in X-ray imaging such as tube voltage (kilovoltage peak; kVp), tube loading (milliampere-second; $\mathrm{mAs}$ ) and focus to image receptor distance ( $\left.\mathrm{d}_{\mathrm{FID}}\right)$, as shown in Table 2, and the X-ray equipment parameters

Table 1 Male and female patients who underwent chest and abdomen digital radiography with an average weight of 50-65 kilogram for males and 45-60 kilogram for females

\begin{tabular}{llll}
\hline Type of X-ray examination & Male & Female & Total \\
\hline Chest (posteroanterior) & 165 & 165 & 330 \\
Abdomen (anteroposterior) & 46 & 46 & 92 \\
\hline
\end{tabular}

Table 2 General information and technical parameters of this study

\begin{tabular}{|c|c|c|c|c|c|c|}
\hline Examination & Gender & $\begin{array}{l}d_{F I D} \\
(\mathrm{~cm})\end{array}$ & Weight (kg) & $\begin{array}{l}\text { Patient thickness, } \\
t_{p}(\mathrm{~cm})\end{array}$ & $\begin{array}{l}\text { Tube voltage, } \\
(k V p)\end{array}$ & $\begin{array}{l}\text { Tube loading, } \\
\text { PIt }_{\text {It }} \text { As) }\end{array}$ \\
\hline Chest (PA) & Male $(n=165)$ & 180 & $62(50-65)$ & $20(17-25)$ & 110 & $\begin{array}{l}1.80 \\
(1.08-4.34)\end{array}$ \\
\hline Chest (PA) & Female $(n=165)$ & 180 & $54(45-60)$ & $20(16-22)$ & 110 & $\begin{array}{l}1.56 \\
(1.05-2.62)\end{array}$ \\
\hline \multirow[t]{2}{*}{ Abdomen (AP) } & Male $(n=34)$ & 100 & $58(50-65)$ & $21(19-27)$ & 85 & $\begin{array}{l}8.45 \pm 1.61 \\
(5.17-12.7)\end{array}$ \\
\hline & Male $(n=12)$ & 100 & $62(50-65)$ & $21(19-26)$ & 80 & $\begin{array}{l}7.10 \pm 0.76 \\
(6.34-8.76)\end{array}$ \\
\hline \multirow[t]{2}{*}{ Abdomen (AP) } & Female $(n=35)$ & 100 & $53(45-60)$ & $20(18-23)$ & 85 & $\begin{array}{l}8.32 \pm 1.46 \\
(5.00-9.12)\end{array}$ \\
\hline & Female $(n=11)$ & 100 & $55(45-60)$ & $20(17-22)$ & 80 & $\begin{array}{l}7.85 \pm 1.08 \\
(6.51-8.71)\end{array}$ \\
\hline
\end{tabular}

$\mathrm{d}_{\mathrm{FID}}=$ focus to image receptor distance, $\mathrm{t}_{\mathrm{p}}=$ patient thickness, $\mathrm{P}_{\mathrm{It}}=$ Tube loading $\mathrm{PA}=$ posteroanterior, $\mathrm{AP}=$ anteroposterior 
such as distance from tube focus to detector (d), X-ray tube output $(\mathrm{Y}(\mathrm{d}))$, half value layer $(\mathrm{HVL})$ and backscatter factor (B), as shown in Table 3.

The $X$-ray tube output $Y(d)$ was measured in clinical situations for different $k \bigvee p$ settings in each $X$-ray examination, as shown in Figure 1. For each patient, the incident air kerma from the exposure parameters can be calculated using Equation (1). ${ }^{9}$

$$
K_{i}=Y(d) P_{I t}\left(\frac{d}{d_{F I D}-t_{p}}\right)^{2}
$$

\section{where}

$\mathrm{K}_{\mathrm{i}}$ is incident air kerma (mGy);
$\mathrm{Y}(\mathrm{d})$ is tube output (mGy/mAs);

$P_{\mathrm{It}}$ is tube loading (mAs);

$\mathrm{d}$ is focus to ionization chamber distance (centimeter; $\mathrm{cm})$;

$d_{F I D}$ is focus to image receptor distance (cm);

tp is patient thickness (cm).

The ESAK can be calculated using Equation (2), ${ }^{9}$ by multiplying incident air kerma with the appropriate backscatter factor for water. Selection of the backscatter was based on the measured HVL, as shown in Figure 2 and the field size used during the examination as recommended in the Technical Reports Series No. 457 "Dosimetry in

Table 3 The $X$-ray equipment parameters of this study

\begin{tabular}{llllll}
\hline Examination & $\begin{array}{l}\text { Distance from tube } \\
\text { focus to detector } \\
\mathbf{d}(\mathbf{c m})\end{array}$ & $\begin{array}{l}\text { Tube voltage } \\
(\mathbf{k V p})\end{array}$ & $\begin{array}{l}\text { Tube output, } \mathbf{( d )} \\
(\mathbf{m G y} / \mathbf{m A s})\end{array}$ & HVL & BSF (B) \\
\hline Chest (PA) & 100 & 110 & 0.092 & 4.36 & 1.46 \\
Abdomen (AP) & 100 & 80 & 0.051 & 3.16 & 1.41 \\
Abdomen (AP) & 100 & 85 & 0.058 & 3.32 & 1.42 \\
\hline
\end{tabular}

$P A=$ posteroanterior, $A P=$ anteroposterior, $\mathrm{Y}(\mathrm{d})=$ tube output, $\mathrm{HVL}=$ half value layer, $\mathrm{BSF}(\mathrm{B})=$ backscatter factor

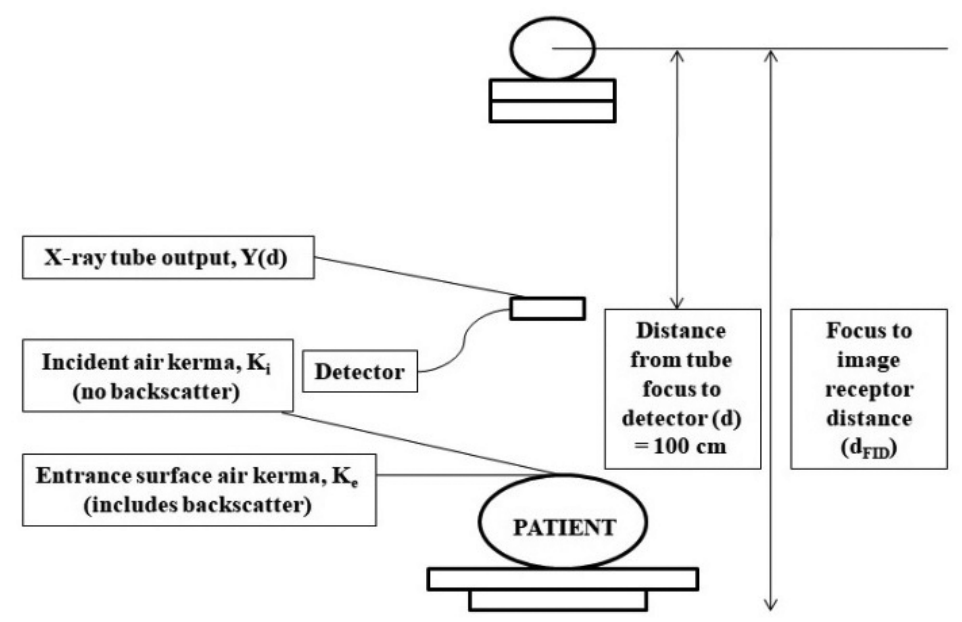

Figure 1 Diagram of the tube output measuring arrangement 

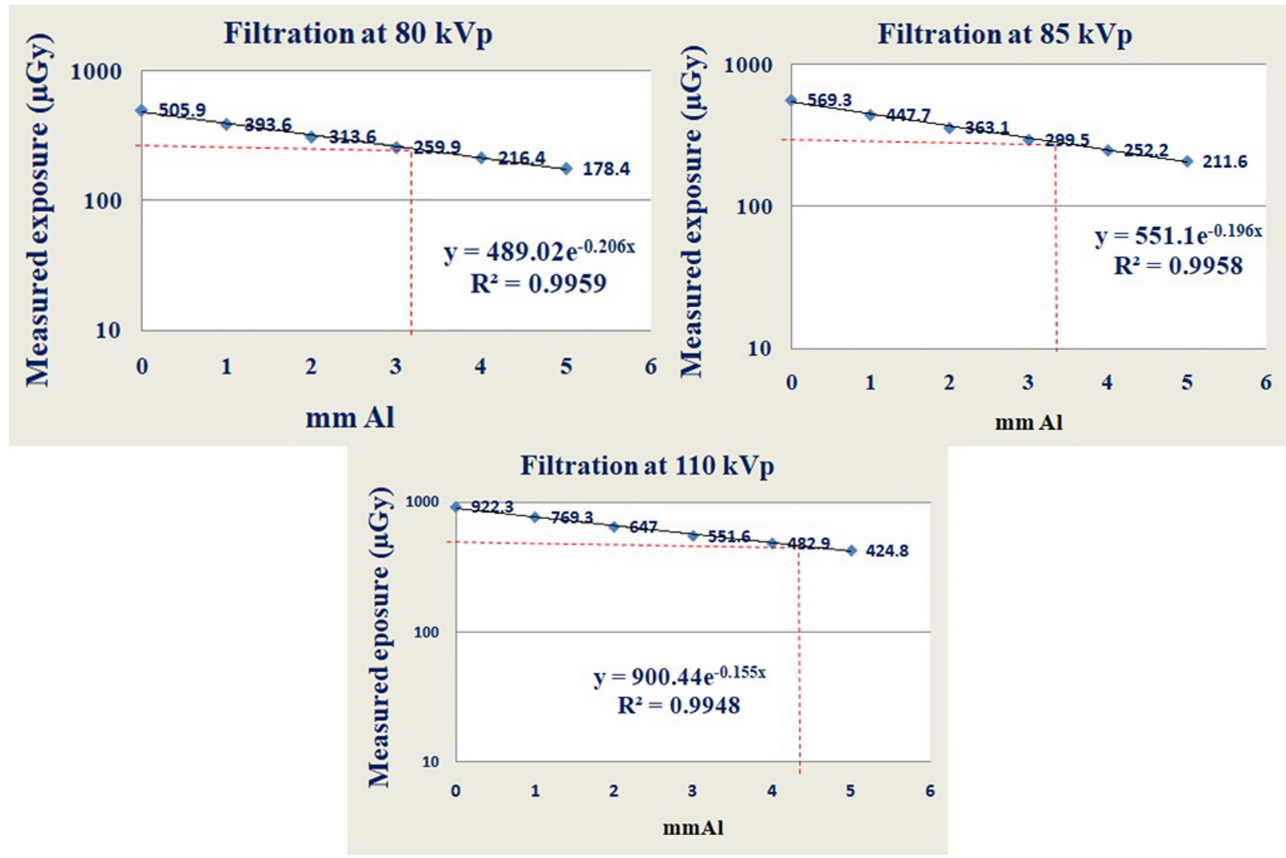

Figure 2 The half value layer (HVL) at (a) 80, (b) 85 and (c) 110 kilovoltage peak (kVp)

Diagnostic Radiology: An International Code of Practice”, International Atomic Energy Agency (IAEA) published in 2007. 6

$$
\mathrm{K}_{\mathrm{e}}=\mathrm{K}_{\mathrm{i}} \mathrm{B}
$$

where:

$\mathrm{K}_{\mathrm{e}}$ is entrance surface air kerma (mGy);

$\mathrm{K}_{\mathrm{i}}$ is incident air kerma (mGy);

$\mathrm{B}$ is backscatter factor.

\section{Results}

The mean ESAK and the third quartile values in female and male patients for chest (PA) and abdomen (AP) digital radiography at the Radiology Department, Chulabhorn Hospital are shown in Table 4.

All of the estimated doses in this study were less than the IAEA reference levels and other research ${ }^{5-8,10-17}$ for chest (PA) and abdomen (AP) digital radiography in female and male patients, as shown in Figure 3 and Figure 4.

The test as to whether the median ESAK between female and male patients is different from each other, using the Mann-Whitney $\cup$ Test, which are non-parametric statistics to test the hypotheses is shown in Table 5 and 6 . If $p$-value $<0.05$, this difference is then considered significant. The findings from the test show that; the median ESAK for chest (PA) digital radiography of both female or male patients is different, as $p$-value $<0.05$. The findings from the test show that the median ESAK for abdomen (AP) digital radiography of neither female or male patients is not different, as $p$-value>0.05.

The findings from the test show that the median ESAK for chest (PA) digital radiography of the female and male patients is different, which could occur from the patient thickness varying across a wide range. 
The standard deviation value of abdomen (AP) digital radiography was higher than chest (PA) digital radiography because the technical parameters varied across a wide range. For example, the tube loading factors extend from 5.0 to $12.7 \mathrm{mAs}$ for abdomen (AP) digital radiography, as shown in Table 2.

Table 4 The measured entrance surface air kerma for different radiographic examinations milligray.

\begin{tabular}{|c|c|c|c|c|c|c|}
\hline \multirow{2}{*}{ Examination } & \multirow{2}{*}{ Gender } & \multicolumn{5}{|c|}{ Entrance surface air kerma (mGy) } \\
\hline & & Third quartile & Mean & S.D. & Max & Min \\
\hline Chest (PA) & Male $(n=165)$ & 0.10 & 0.09 & 0.03 & 0.22 & 0.05 \\
\hline Chest (PA) & Female $(n=165)$ & 0.09 & 0.08 & 0.02 & 0.14 & 0.05 \\
\hline Abdomen (AP) & Male $(n=46)$ & 1.20 & 1.06 & 0.22 & 1.72 & 0.65 \\
\hline Abdomen (AP) & Female $(n=46)$ & 1.11 & 0.98 & 0.17 & 1.25 & 0.62 \\
\hline
\end{tabular}

$\mathrm{mGy}=$ milligray, $\mathrm{PA}=$ posteroanterior, $\mathrm{AP}=$ anteroposterior, S.D.=standard deviation

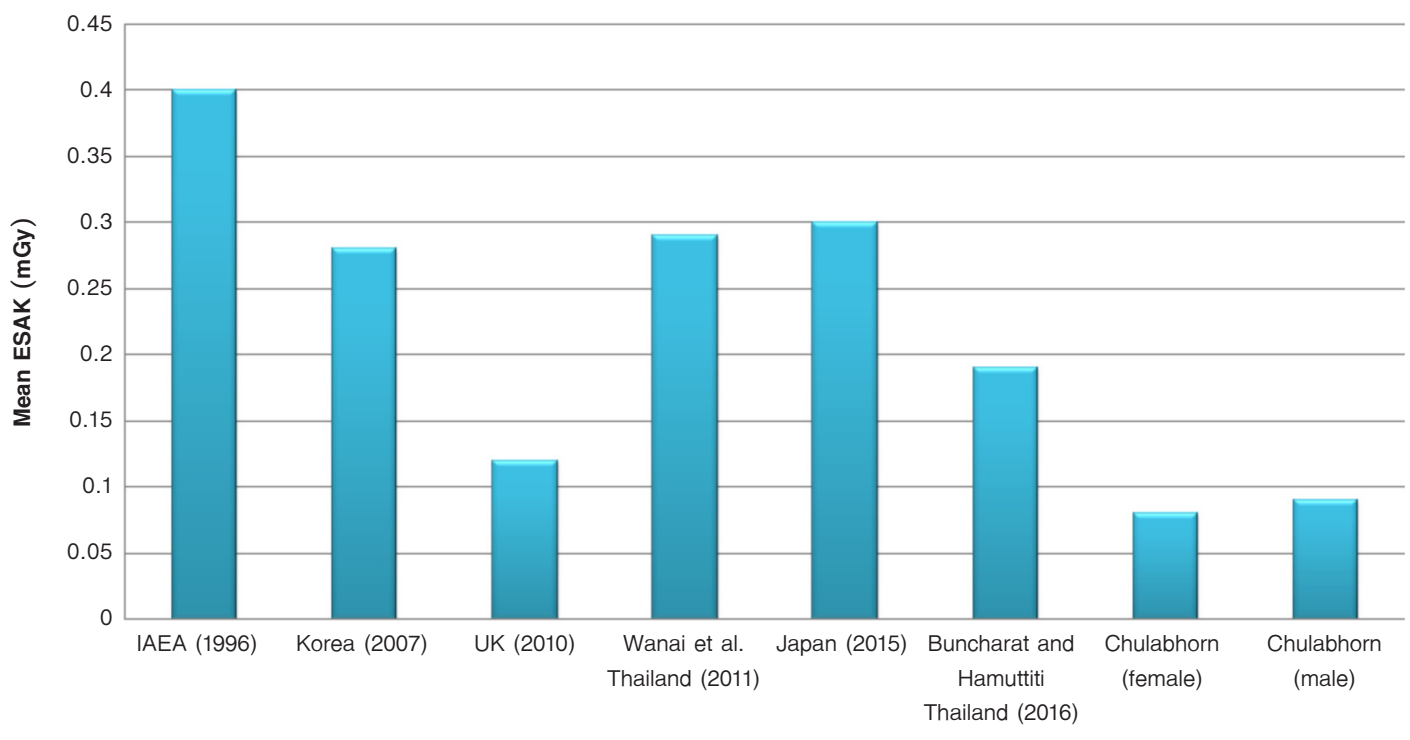

Other research and Chulabhorn Hospital

Figure 3 The mean entrance surface air kerma comparison with other guidelines for adult postero-anterior chest examination 


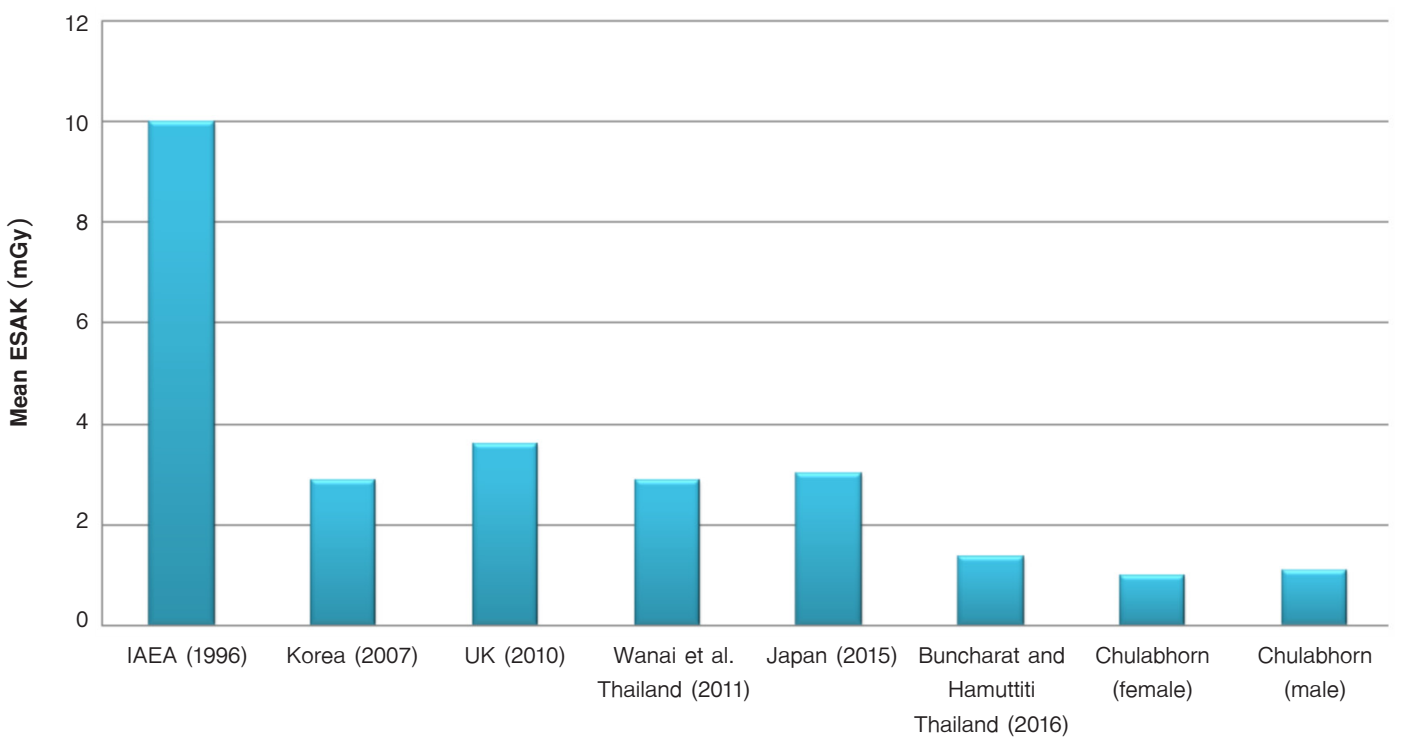

Other research and Chulabhorn Hospital

Figure 4 The mean entrance surface air kerma comparison with other guidelines for adult antero-posterior abdomen examination

Table 5 Comparison of median entrance surface air kerma between female and male patients for adult postero-anterior chest examination

\begin{tabular}{lll}
\hline Examination & Gender & Median entrance surface air kerma (mGy) \\
\hline Chest (PA) & Male $(n=165)$ & 0.091 \\
Chest (PA) & Female $(n=165)$ & 0.077 \\
Male vs female & p-value & 0.001 \\
\hline
\end{tabular}

Data are represented as median. Statistical analysis was performed by Mann Whitney $U$ test.

mGy=milligray, PA=posteroanterior

Table 6 Comparison of median entrance surface air kerma between female and male patients for adult antero-posterior abdomen examination

\begin{tabular}{lll}
\hline Examination & Gender & Median entrance surface air kerma (mGy) \\
\hline Abdomen (AP) & Male $(n=46)$ & 0.993 \\
Abdomen (AP) & Female $(n=46)$ & 0.969 \\
Male vs female & p-value & 0.151 \\
\hline
\end{tabular}

Data are represented as median. Statistical analysis was performed by Mann Whitney $U$ test.

$m G y=$ milligray, $\mathrm{AP}=$ anteroposterior 


\section{Discussion}

Comparison of patient doses for digital radiography between this study and Buncharat and Hamuttiti ${ }^{6}$, the mean ESAK values for chest (PA) digital radiography in male and female patients at Chulabhorn Hospital were lower than the study of Buncharat and Hamuttiti ${ }^{6}$ for digital radiography, as shown in Figure 5, because of the high $\mathrm{kVp}$ technique (110 kVp) used in this study. Buncharat and Hamuttiti $^{6}$ used technical parameters that varied across a wide range. For example, the exposure factors extend from 65.8 to $116.6 \mathrm{kVp}$ and from 3.3 to $32 \mathrm{mAs}$, for chest (PA) digital radiography.

The mean ESAK values for abdomen (AP) digital radiography in male and female patients in this study were lower than the study of Buncharat and Hamuttiti ${ }^{6}$ as shown in Figure 6, because of using the automatic exposure control. Buncharat and Hamuttiti ${ }^{6}$ used technical parameters that varied across a wide range. For example, the exposure factors extend from 62.9 to $97.9 \mathrm{kVp}$ and from 8 to $50 \mathrm{mAs}$, for abdomen (AP) digital radiography.

In practice, the image quality is expressed as: the adequate contrast on radiographs by the combination of exposure factors, such as: tube voltage and tube-current time product. It is well known that the lower the voltage used for any examination, the higher the tube-current time product required to achieve better contrast on the image, and hence the higher the patient dose. ${ }^{18}$

The mean ESAK values for chest PA and abdomen $A P$ radiography in male and female patients using digital imaging devices at Chulabhorn Hospital were lower than the reference levels of IAEA and other research, ${ }^{5-8,10-17}$ because of using a high $\mathrm{kVp}$ technique for the chest and the automatic exposure control for the abdomen. Furthermore, the flat panel detector in the digital imaging device has better detective quantum efficiency, ${ }^{18}$ which helps in reducing patient dosage without affecting the quality of the image. Also, digital post-processing techniques can help in manipulating the image for better contrast, in case the images are obtained by lower mAs and higher tube potentials or lower radiation doses. As well as Thai people is quite smaller than the Westerners. ${ }^{5-8,10-17}$ We studied only the digital radiography system that literally provides the lowest radiation dose compared with screen film and computed radiography.

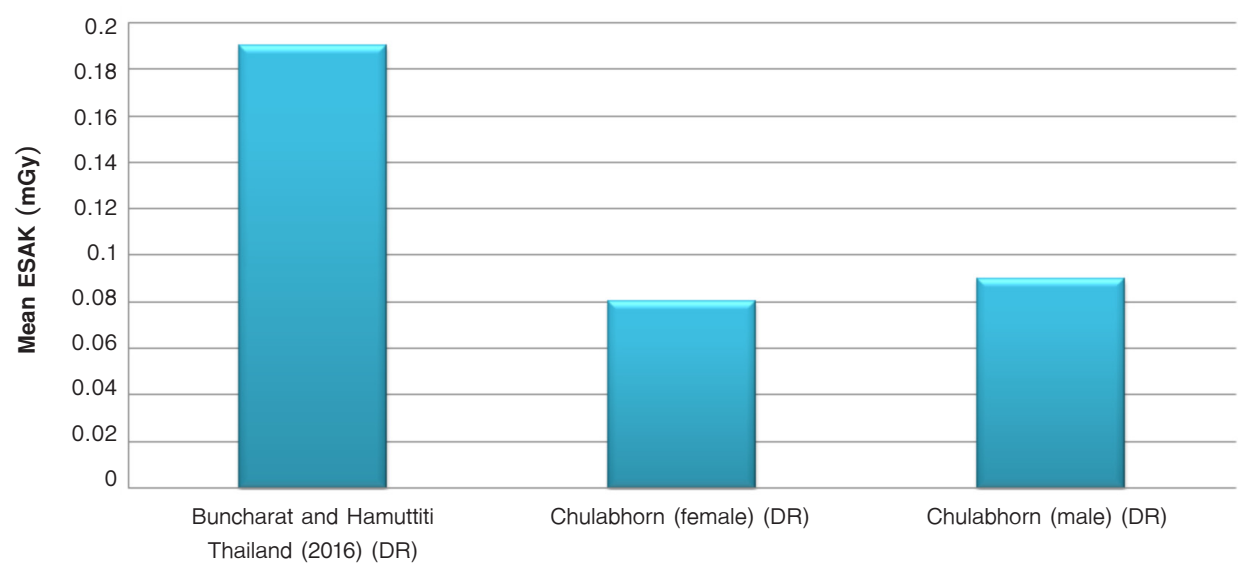

Buncharat and Hamuttiti and Chulabhorn Hospital

Figure 5 The mean entrance surface air kerma comparison with Buncharat and Hamuttiti ${ }^{6}$ for chest (posteroanterior) digital radiography 


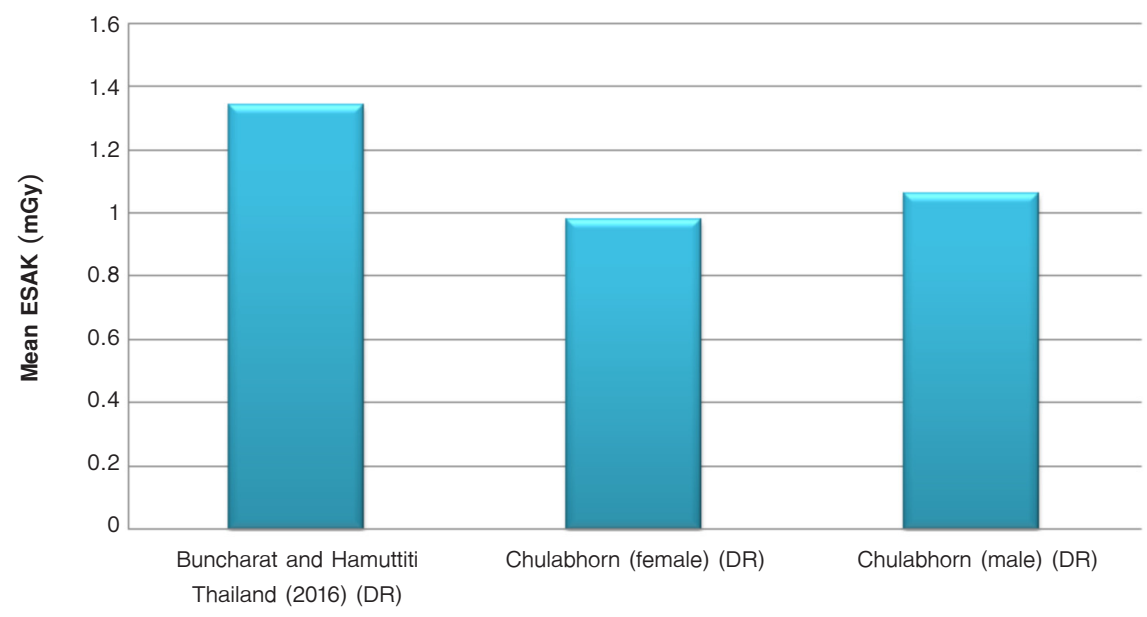

Buncharat and Hamuttiti and Chulabhorn Hospital

Figure 6 The mean entrance surface air kerma comparison with Buncharat and Hamuttiti ${ }^{6}$ for abdomen (anteroposterior) digital radiography

From various literature reviews, some researchers $^{2,19,20}$ studied comparisons of patient doses for screenfilm radiography, computed radiography, and digital radiography; for example, Aldrich et al. ${ }^{2}$ found that the mean ESAK values received in patients for chest PA and abdomen AP radiography through digital radiography were lower than for computed radiography and the screen film system. Nevertheless, it is important to consider the technique parameters used in X-ray imaging as the must be adjusted according to the patient's size and the X-ray device used.

Flat panel detectors can reduce radiation dose by about twofold to threefold for adult imaging, compared with computed radiography for the same image quality, owing to the better quantum absorption and conversion efficiency associated with that technology. ${ }^{18}$

Radiological imaging technology has evolved and developed progressively. It is, therefore, important to employ and adapt these advanced technologies to X-ray imaging so that effective imaging can be achieved while reducing the risk associated with radiation exposure.

\section{Conclusion}

The mean entrance surface air kerma values of this study were less than the diagnostic reference levels from the IAEA 1996, Korea 2007, United Kingdom 2010, and Japan 2015, in all projections. Patient doses (ESAK) in chest (PA) and abdomen (AP) digital radiography at Chulabhorn Hospital were less than the other guidelines.

Although there are several researchers who determine radiation dose from various types of radiographic examination and set up a standard dose for each radiographic examination, the use of such information to assess the radiation dose for patients in each hospital is not possible. This is because there are different variables such as the type of X-ray devices used, X-ray techniques and $X$-ray tube output. Therefore, it is recommended that each hospital should establish its own ESAK levels that are appropriate to its X-ray equipment and determine a standard radiation dose for each type of radiographic examinations and compare the data with other international organisations and research in order to prevent any harm from radiation and to control the quality in the field of radio- 
logy. The results should be used to improve and future studies.

\section{Acknowledgement}

I would like to acknowledge all those who gave me the opportunity to complete this research. Furthermore, I appreciate the co-operation of both patients and the staff of Department of Diagnostic and Interventional Radiology at Chulabhorn Hospital.

\section{References}

1. International Atomic Energy Agency. Radiation biology: a handbook for teachers and students. Vienna: IAEA; 2010.

2. Aldrich JE, Duran E, Dunlop P, Mayo JR. Optimization of dose and image quality for computed radiography and digital radiography. J Digit Imaging 2006;19:126-31.

3. International Atomic Energy Agency. Diagnostic radiology physics: a handbook for teachers and students. Vienna: IAEA; 2014.

4. Diagnostic reference levels in medical imaging: review and additional advice. Ann ICRP 2001;31:33-52.

5. Kim YH, Choi JH, Kim CK, Kim JM, Kim SS, Oh YW, et al. Patient dose measurements in diagnostic radiology procedures in Korea. Radiat Prot Dosimetry 2007;123:540-5.

6. Buncharat S, Hamuttiti P. Patient doses in simple radiographic examinations in Trang, Phatthalung and Satun Provinces in Transition from X-ray film to computed radiography. J Health Sci 2016;25:632-40.

7. Wanai A, Kongaew P. Entrance surface dose level of common diagnostic X-ray examinations at Songklanagarind Hospital. Songkla Med J 2011;29:57-64.

8. Yonekura Y. Diagnostic reference levels based on latest surveys in Japan - Japan DRLs 2015 [monograph on the Internet]. Chiba: Japanese Network for Research and Information on Medical Exposure; 2015 [cited 2016 Nov 4]. Available from: http://www.radher.jp/J-RIME/report/ DRLhoukokusyoEng.pdf

9. International Atomic Energy Agency. Technical reports series no. 457 Dosimetry in diagnostic radiology: an international code of practice. Vienna: IAEA; 2007
10. Hart D, Hillier M, Shrimpton P. Doses to patients from radiographic and fluoroscopic X-ray imaging procedures in the UK-2010 review. Oxfordshire: Health Protection Agency Centre for Radiation, Chemical and Environmental Hazards; 2010.

11. Rasuli B, Mahmoud-Pashazadeh A, Ghorbani M, Juybari RT, Naserpour M. Patient dose measurement in common medical X-ray examinations in Iran. J Appl Clin Med Phys 2016;17: 374-86.

12. Owoade LR, Sambo I, Tijani SA. Assessment of entrance surface air kerma in patients undergoing chest X-ray from conventional diagnostic radiology in Ogun State, Nigeria. Int $\mathrm{J}$ Med Sci 2015;7:117-20.

13. Akpochafor MO, Omojola AD, Adeneye SO, Aweda MA, Ajayi HB. Determination of reference dose levels among selected X-ray centers in Lagos State, South-West Nigeria. J Clin Sci 2016;13:167-72.

14. Sookpeng S, Tongtidram T, Saengkam P, Sirisoontorn I. Entrance skin dose of patient undergoing chest radiography among hospitals in Changwat Phitsanulok. J Health Sci 2008;17:59-67.

15. Thungsuk S, Sodkokkrud P, Jaovisidha S, Thungsuk S, Kumsang $Y$, Jatchavala $\mathrm{J}$, et al. Evaluation of radiation skin dose in pediatric chest radiography. Rama Med J 2016;39: 55-61.

16. Wichathorntrakun W, Wongsanon S, Kheonkaew B. Skin radiation dose of patient undergoing chest radiography in Srinagarind Hospital, Faculty of Medicine, Khon Kaen University. Srinagarind Med J 2010;25:120-4.

17. Singkavongsay A, Saita K. Patient entrance surface dose in diagnostic radiography in hospitals in the central part of Thailand. Bulletin of the Department of Medical Sciences 2008;50:338-45.

18. Bushberg JT, Seibert JA, Leidholdt EM, Boone JM. The essential physics of medical imaging. 2nd ed. Am J Roentgenol 2003; 180:596.

19. Bansal GJ. Digital radiography. A comparison with modern conventional imaging. Postgrad Med J 2006;82:425-8.

20. Masoud AO, Muhogora WE, Msaki PK. Assessment of patient dose and optimization levels in chest and abdomen CR examinations at referral hospitals in Tanzania. J Appl Clin Med Phys 2015;16:435-41. 